\title{
Aspectos bucais da síndrome de Rubinstein-Taybi: relato de dois casos clínicos
}

- Fabiana Mesquita Barros Departamento de Estomatologia, Faculdade de Odontologia, Universidade de São Paulo, São Paulo, SP, Brasil • Letycia lida Graduanda, Faculdade de Odontologia, Universidade de São Paulo, São Paulo, SP, Brasil - Thais Dutra Alves Departamento de Estomatologia, Faculdade de Odontologia, Universidade de São Paulo, São Paulo, SP, Brasil • Aparecida Angélica Castorino Departamento de Estomatologia, Faculdade de Odontologia, Universidade de São Paulo, São Paulo, SP, Brasil - Fabiana Martins Departamento de Estomatologia, Faculdade de Odontologia, Universidade de São Paulo, São Paulo, SP, Brasil • Marina Gallottini Departamento de Estomatologia, Faculdade de Odontologia, Universidade de São Paulo, São Paulo, SP, Brasil

RESUMO | A síndrome de Rubinstein-Taybi é uma doença multissistêmica genética rara caracterizada por dimorfismo facial típico, retardo de crescimento, deficiência mental e múltiplas anormalidades dentárias. Este relato de caso descreve os achados orofaciais da síndrome de Rubinstein-Taybi que afetou um menino brasileiro de onze anos de idade e uma menina de dez anos. As descobertas orais dos pacientes, tais como lábios superiores finos, retenção prolongada dos dentes decíduos e hipodontia são relatados, e o manejo clínico é discutido.

DESCRITORES | Síndrome Rubinstein-Taybi; Manifestações Orais; Relato de Caso.

ABSTRACT | Oral aspects of Rubinstein-Taybi syndrome: report of two cases • Rubinstein-Taybi syndrome is a rare genetic multisystem disorder characterized by typical facial dimorphism, slow growth, mental deficiency, and multiple dental abnormalities. This case report describes the oral-facial findings of Rubinstein-Taybi syndrome affecting a 11-year-old Brazilian male, and a 10-year-old female. The oral findings of the patients, such as thin upper lips, prolonged retention of the primary teeth, and hypodontia are reported, and the clinical management is discussed.

DESCRIPTORS | Rubinstein-Taybi Syndrome; Oral Manifestations; Case Report.

AUTOR CORRESPONDENTE | • Fabiana Mesquita Barros Departamento de Estomatologia, Faculdade de Odontologia, Universidade de São Paulo • Av. Professor Lineu Prestes, 2227, Cidade Universitária São Paulo, SP, Brasil • 05508-000 E-mail: fabianamesquitabarros@usp.br

- Received Oct 10, 2017 • Accepted Nov 9, 2017

- Dol http://dx.doi.org/10.11606/issn.2357-8041.clrd.2017.139579 


\section{INTRODUÇÃO}

A Síndrome de Rubinstein-Taybi (RSTS) foi primeiramente descrita em 1963, sendo caracterizada por múltiplas anomalias físicas congênitas, como face dismórfica, polegares largos, dedos grandes, baixa estatura e retardo mental. É uma doença genética rara com prevalência de 1 em 100.000 a 125.000 recém-nascidos vivos. ${ }^{1}$ No Brasil, a Associação Brasileira da Síndrome de Rubinstein-Taybi estima que há aproximadamente 143 indivíduos com a síndrome vivendo no país. ${ }^{2}$

A RSTS pode ser transmitida como doença autossômica dominante, contudo, a maior parte das ocorrências se desenvolve esporadicamente a partir de uma mutação de novo. ${ }^{3}$ A causa genética da síndrome envolve pontos de interrupção em uma região restrita do cromossomo $16 \mathrm{p} 13.3$, havendo mutações no gene CBP ou microdeleções de um único éxon até centenas de quilobases. ${ }^{4-7}$ Outra mutação, no gene homólogo p300, no cromossomo 22q13.2, foi descrita em indivíduos afetados. ${ }^{8}$ Estes genes possuem semelhanças quanto à estrutura primária, atividade da histona acetiltransferase (HAT) e quanto à função de coativadores da transcrição. 8,9

O diagnóstico da síndrome é majoritariamente clínico e complexo em função da ausência de consenso de critérios. Frequentemente é realizado ao nascimento ou durante a infância através da observação de características típicas em avaliações psico-físicas e dismorfológicas. , $^{4}$

As características da RSTS incluem malformações esqueléticas, atraso no crescimento e desenvolvimento psicomotor e dimorfismos craniofaciais. Aspectos adicionais como anormalidades oculares, cardiopatias congênitas, problemas renais e obesidade podem estar presentes e os sinais e sintomas variam entre os indivíduos afetados. As pessoas com RSTS apresentam risco aumentado de desenvolver neoplasias benignas e malignas, dos quais se destacam tumores cerebrais e leucemia. ${ }^{6}$

As alterações bucais foram poucas vezes descritas na literatura e incluem palato alto e estreito, retromicrognatia, lábio superior fino, pequena abertura bucal e úvula bífida. Em raros casos foi descrita fissura labial e palatina..$^{910} \mathrm{~A}$ maioria dos indivíduos afetados apresenta máoclusão, incluindo mordida cruzada e apinhamento dental. Alterações de desenvolvimento dentário como hipoplasia de esmalte, dentes de Hutchinson e tálon cúspide foram descritas. ${ }^{4}$

O conjunto de manifestações físicas, anatômicas e funcionais, associado às alterações comportamentais dos indivíduos com a RSTS, representa um desafio para o cirurgião-dentista durante o tratamento odontológico, em função da complexidade anatômica orofacial, adequação do manejo clínico do paciente, e dificuldade para comunicação e colaboração com o tratamento ambulatorial.

Dentro desse contexto, relatamos os aspectos orofaciais de dois pacientes com RSTS, bem como os distúrbios médicos relevantes encontrados, a fim de fornecer informações que auxiliem o cirurgião-dentista no planejamento e tratamento odontológico de pessoas afetadas por tal síndrome.

\section{RELATO DE CASOS}

Caso 1: Paciente do sexo masculino, com 11 anos de idade, diagnosticado com a RSTS no primeiro ano de vida, foi encaminhado à clínica odontológica do Centro de Atendimento a Pacientes Especiais da Faculdade de Odontologia da Universidade de São Paulo (CAPE/FOUSP) com a queixa da mãe de "demora na troca dos dentes de leite".

Durante a anamnese, a mãe negou antecedentes familiares associados a síndromes e relatou período pré-natal sem intercorrências. No entanto, o parto foi prematuro, com 32 semanas de gestação. 
Após o nascimento, o paciente apresentou parâmetros de sinais vitais alterados e descompensação cardiológica e pulmonar, sendo internado em Unidade de Terapia Intensiva (UTI). Aos 11 dias de vida foi submetido à cirurgia cardíaca para correção e fechamento do canal arterial aberto (PCA).

A cardiopatia congênita associada a outras características clínicas identificadas ao nascimento tais como fácies, fissura palatina e dedos grandes, induziram investigação do cariótipo, levando à confirmação do diagnóstico de RTS.

Aos três anos de idade, o paciente foi submetido a correção de fenda palatina pós-forame completa. Posteriormente, aos cinco anos de idade, durante os exames de rotina, o pediatra diagnosticou a síndrome de Wolff-Parkinson-White (WPW) através de eletrocardiograma (ECG). Neste ano o paciente também foi diagnosticado com hipotireoidismo. Fazia uso de levotiroxina e não realizou a correção da WPW.

Aos onze anos, quando nos procurou para tratamento odontológico, observamos retardo mental severo, fácies típica da RSTS caracterizada por nariz pontiagudo e em forma de bico, hipoplasia do terço médio da face, hipertelorismo, cabelos espessos, sobrancelhas arqueadas e altas, orelhas com baixa implantação, fístulas cegas entre o antítrago e antélice (Figura 1A e B). Também foram identificados mãos e pés pequenos e achatados, sendo que os dedos das mãos eram grandes e largos (Figura 1C).

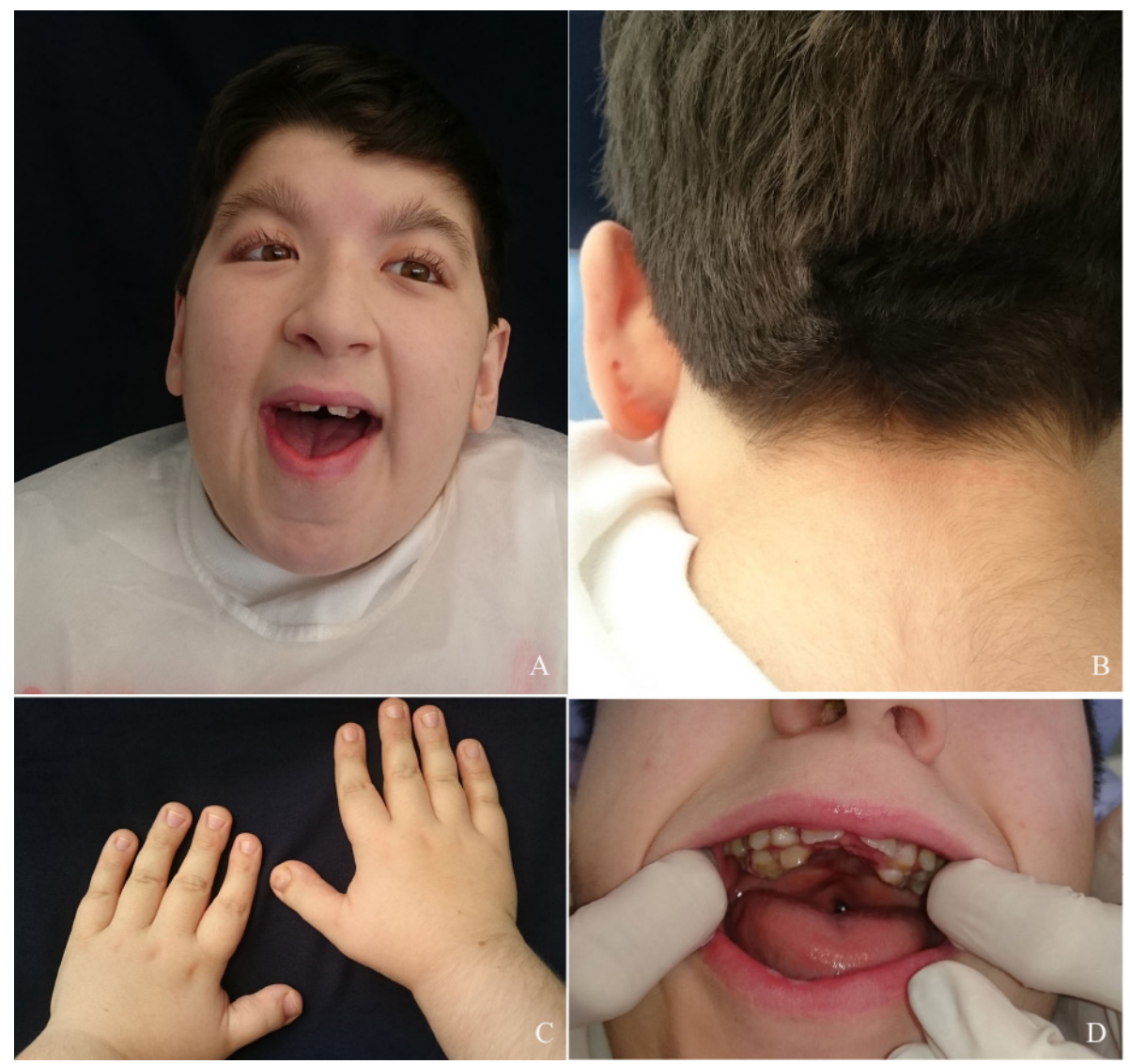

Figura 1 | Caso 1, menino, 11 anos de idade. A) Fácies dismórfica, nariz pontiagudo, sobrancelhas altas e arqueadas, hipertelorismo, estrabismo, lábio fino e sulco labiomental profundo. B) Cabelos espessos, orelha com baixa implantação e fístulas cegas entre o antítrago e antélice. C) Dedos e polegares grandes e largos e mãos pequenas. D) Palato arqueado e estreito, retenção prolongada de dentes decíduos, apinhamento dental, hipotonia muscular e fissura palatina corrigida. 
Durante o exame intraoral, observamos micrognatia, retenção prolongada dos dentes decíduos, apinhamento dental, hipotonia muscular, palato ogival e estreito, e fissura palatina corrigida. Não foram identificadas cáries durante o exame, e pouco acúmulo de biofilme foi notado (Figura 1D).

O paciente não formulava linguagem falada e mostrou-se pouco cooperativo durante a consulta odontológica. Como ficava muito agitado e nervoso durante as tentativas de abordagem clínica, diante do risco de arritmia, a dentista referiu o paciente ao cardiologista para avaliação e possível correção da WPW. O cardiologista optou pela destruição da via de condução elétrica adicional cardíaca por meio de ablação por radiofrequência. O planejamento odontológico inclui exodontia dos dentes decíduos retidos, após a alta do cardiologista.

Caso 2: Paciente do sexo feminino, dez anos de idade, leucoderma, compareceu ao ambulatório para acompanhamento de rotina. A anamnese revelou parto a termo e sem complicações e desenvolvimento neuropsicomotor atrasado em relação à coordenação motora ampla, linguagem e fala.
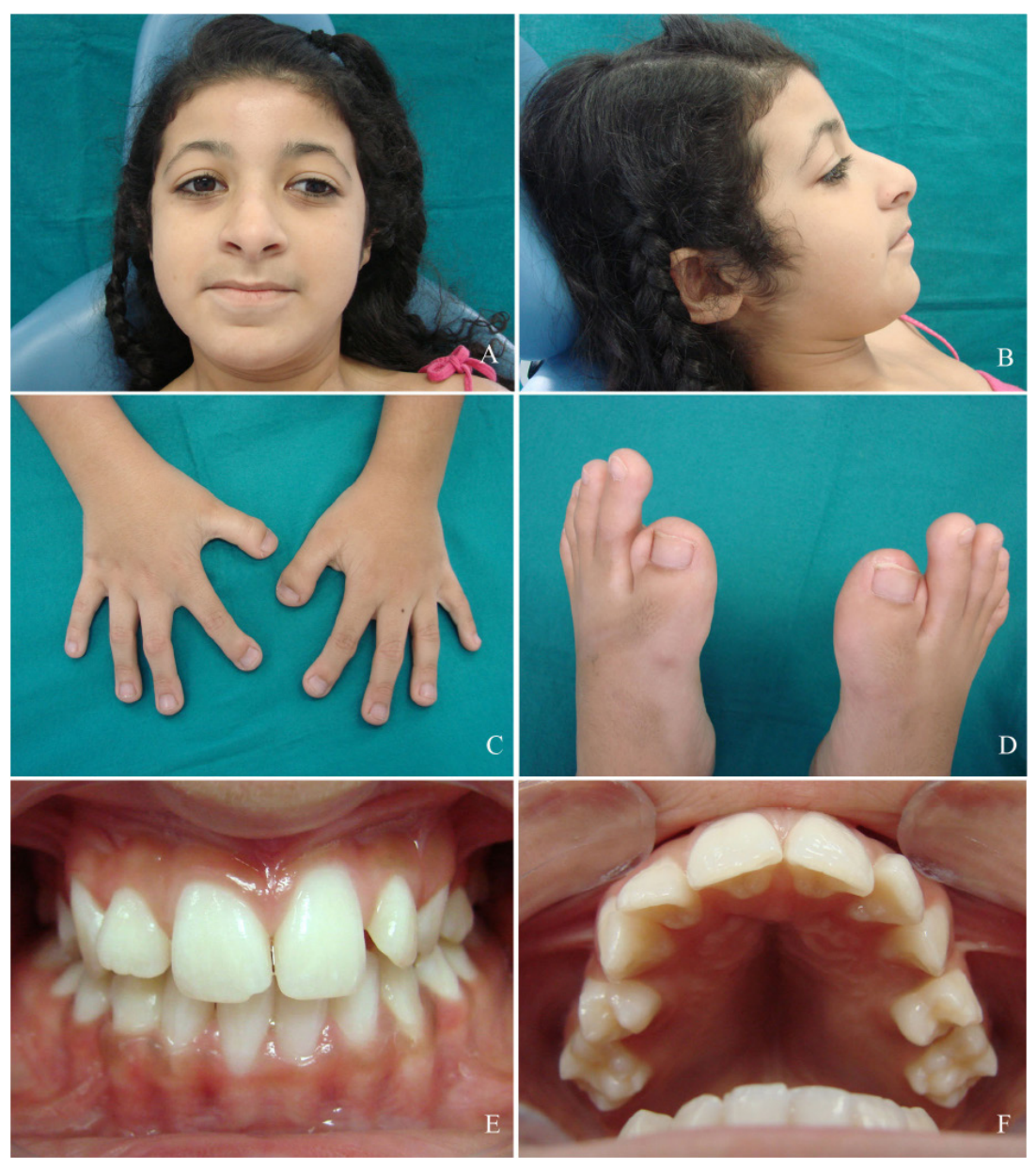

Figura 2 | Caso 2, menina, 10 anos de idade. A) Paciente de RSTS com cabelos espessos, sobrancelhas arqueadas, fendas palpebrais antimongoloides, estrabismo, nariz adunco e lábio fino. B) Cabelos grossos, hirsutismo e orelha de baixa implantação. C) Polegares largos e mãos pequenas. D) Dedões dos pés alterados e largos. E) Oclusão equilibrada e giroversão discreta dos dentes 12 e 22. F) Cíngulo proeminente nos dentes incisivos, dente 14 girovertido, anodontia dos segundos pré-molares superiores e palato profundo e estreito. 
A história médica revelou episódios prévios de pneumonia, refluxo gastroesofágico, estrabismo e miopia. A história odontológica revelou mordida cruzada posterior bilateral, corrigida com ortopedia funcional dos cinco aos nove anos de idade.

Durante o exame clínico pudemos observar baixa estatura, cabeça pequena, cabelos grossos, nariz bicudo, fendas palpebrais oblíquas antimongoloide, sobrancelhas curvadas e hirsutismo (Figura 2A e B). Além disso, observamos polegares das mãos largos e dedos dos pés grandes (Figura $2 \mathrm{C}$ e D).

$\mathrm{O}$ exame intrabucal revelou palato arqueado, úvula bífida, hipoplasia de maxila, hipodondia dos segundos pré-molares superiores (Figura 2E e F). Foi realizada orientação de higiene e profilaxia dental. Apesar de haver giroversão de pré-molar superior, a mãe optou por não retomar o tratamento ortodôntico.

\section{DISCUSSÃO}

Por ser extremamente rara, são escassos os relatos e publicações de série de casos dos aspectos orofaciais da RSTS. A série mais extensa que discorre sobre as características orodentárias foi publicada por Hennekam e Van Doorne, ${ }^{9}$ que descreveram os achados de 45 pacientes holandeses com a síndrome. De acordo com esses autores, os principais achados não-dentais foram lábio superior fino, abertura oral pequena, retro/micrognatia e palato estreito. Todas essas características foram observadas nos casos aqui relatados. Além desses, nossos casos têm história de fenda palatina e de úvula bífida.

As tálon cúspides são raras em indivíduos não afetados pela RSTS e encontradas na grande maioria dos indivíduos com a RSTS. Mas, nos nossos casos, apenas observamos o cíngulo dos dentes incisivos superiores proeminentes e não a tálon cúspide.

A literatura geralmente comenta que os pacientes com RTS têm índice aumentado de cárie e de doença periodontal. Nos casos aqui descritos os pacientes não exibiam cáries. Uma explicação provável é o acompanhamento odontológico periódico que esses pacientes recebem com foco na prevenção de cárie e doença periodontal desde a primeira infância. Apesar do retardo mental e motor profundos, os pais e responsáveis são motivados e orientados para realizar os cuidados de higiene dental.

O caso 1 exigiria tratamento odontológico mais invasivo, uma vez que vários dentes decíduos com retenção prolongada teriam que ser extraídos. No entanto, o estresse e a agitação que o tratamento odontológico em paciente não colaborativo poderia trazer representariam um risco eminente de arritmia e de fibrilação atrial paroxística, dado que a WPW ainda não havia sido tratada. $\mathrm{O}$ encaminhamento ao médico cardiologista, feito pelo dentista, salienta a importância deste profissional da saúde na preservação da homeostase do paciente. Corrigida a síndrome de WPW, o paciente passou a ser atendido normalmente em ambulatório. $\mathrm{O}$ condicionamento psicológico desses pacientes é, muitas vezes, demorado, mas nossa experiência tem mostrado que eles acabam se tornando colaborativos.

O caso 2 é um exemplo de como o contato permanente com o dentista facilita a aceitação do paciente. Mesmo com retardo mental e psicomotor importantes, ela colabora com as intervenções em consultório e consegue manter bom controle de biofilme em casa.

\section{CONCLUSÕES}

Os dentistas, como profissionais da saúde, devem ter a habilidade de antecipar possíveis situações de emergência médica, para conduzir o tratamento odontológico de forma segura em pessoas sistemicamente comprometidas. 


\section{REFERÊNCIAS}

1. McKusick VA, Kniffin CL. \#180849 Rubinstein-Taybi Sindrome 1; RSTS1 [Internet] Baltimore: Online Mendelian Inheritance in Man, 2015 [citado em 2017 out 7]. Disponível em: https://www.omim.org/entry/180849.

2. ArtsBrasil.org.br [Internet]. São Paulo: Associação Brasileira dos Familiares e Amigos Portadores da Síndrome de Rubinstein-Taybi, 2017 [citado em 2017 out 7]. Disponível em: http://www.artsbrasil.org.br/

3. Roelfsema JH, Peters DJM. Rubinstein-Taybi syndrome: clinical and molecular overview. Expert Rev Mol Med. 2007;9(23):1-16. doi: 10.1017/S1462399407000415.

4. Tirali RE, Sar C, Cehreli SB. Oro-facio-dental findings of Rubinstein-Taybi Syndrome as a useful diagnostic feature. J Clin Diagn Res. 2014;8(1):276-8. doi: 10.7860/ JCDR/2014/6710.3929.
5. Hennekam RC. Rubinstein-Taybi syndrome. Eur J Hum Genet. 2006;14(9):981-5. doi: 10.1038/sj.ejhg.5201594.

6. Morales-Chávez MC. Dental management of a patient with Rubinstein-Taybisyndrome. Spec Care Dentist. 2010;30(3):124-6. doi:10.1111/j.1754-4505.2010.00137.x.

7. McManus KJ, Hendzel MJ. CBP, a transcriptional coactivator and acetyltransferase. Biochem Cell Biol. 2001;79(3):253-66.

8. Bannister AJ, Kouzarides T. The CBP co-activator is a histone acetyltransferase. Nature. 1996;384(6610):641-3. doi: 10.1038/384641ao.

9. Hennekam RC, Van Doorne JM. Oral aspects of RubinsteinTaybi syndrome. Am J Med Genet Suppl. 1990;6:42-7.

10. Davidovich E, Eimerl D, Peretz B. Dental treatment of a child with Rubinstein-Taybi syndrome. Pediatr Dent. 2005;27(5):385-8. 